\title{
Laboratory Evaluation of Dimensional Changes of Different Elastomeric Impression Materials Using 3D Laser Scanner
}

\author{
Ahmed Abd-Al Hamed ${ }^{1}$, Safia H. El-Gharabawy ${ }^{2}$, Fayza Al-Abbassy ${ }^{3}$, Abd ElsalamA. Abd Elsalam ${ }^{4}$ \\ ${ }^{1}$ Professor of Prosthodontics, Alexandria University Faculty of Dentistry, Alexandria, Egypt \\ ${ }^{2}$ Professor of Prosthodontics, Alexandria University Faculty of Dentistry, Alexandria, Egypt \\ ${ }^{3}$ Professor of Biomaterial, Alexandria University Faculty of Dentistry, Alexandria, Egypt \\ ${ }^{4}$ BDS, Faculty of Dentistry, Benghazi University, MS, Alexandria University, Egypt
}

\begin{abstract}
Aim of the work: To evaluate and compare the dimensional changes of three different elastomeric impression materials after poured at different time intervals by using three-dimensional (3D) laser scanner and image software program. Materials and methods: The 3 groups of elastomeric impression materials used.The45 Impressions, 15 with vinylpolysiloxane, 15 with polyether and 15 with vinylsiloxanether, of typodont model, poured in Type IV stone after1 hour, 1 day and 1 week. The model and casts were digitized by three-dimensional (3D) laser scanner. Premium software superimposed a standard model with the mastercasts and the difference between the images analyses. Results and Conclusions: All reference points on the master casts obtained from all elastomeric impression materials after one hour and one day showed little changes than the standard model. Concerning the time intervals for pouring the elastomeric impression materials. Both polyether and vinylsiloxanether showed significant changes of difference points after one week of pouring the impressions. The vinylpolysiloxane impression material doesn't showed these changes after one week which means that its dimensional stable than the other one.
\end{abstract}

Keywords: Accuracy, Elastomers, Impression, 3D laser scanner, Superimposition measurement

\section{Introduction}

The clinical success of prosthodontic procedures is dependent, in part, upon the dimensional accuracy of elastomeric impression materials and the impression procedures. It is important that the model of the oral cavity is an accurate three dimensional replica, because the prosthesis is made on this model and therefore, it directly effects the fit of the indirect restoration.[1]

All elastomeric impression materials experience shrinkage during setting.[2]

For this reason, dimensional stability of impression materials has been widely discussed in the dental literature.[3]

There appears to be no consensus in the literature on the measuring device that should be used to evaluate the accuracy of impression materials.

Measurement of the dimensional changes of impression materials requires accurate equipment. Previously, some studies evaluate dimensional changes associated with different impression material where the linear distance between two reference points is measured manually by microscopes and calipers.[1]

Today's three-dimensional (3D) sensor technology provides new potential alternatives to replace the manual measurements.
In this study was evaluate and compare of dimensional accuracy of elastomeric impression materials by using threedimensional (3D) laser scanner with special software, after poured at different time intervals.

\section{Materials and Methods}

This study had been done in the Removable Prosthodontic, Faculty of Dentistry, Alexandria University and $\mathrm{R}+\mathrm{K}$ $\mathrm{CAD} / \mathrm{CAM}$ Technologie $\mathrm{GmbH} \&$ Co. KG Berlin (Germany).

This in-vitro study was conducted on maxillary dentulous typodont model to evaluate and compare the dimensional changes of three different elastomeric impression materials after poured the impressionsat 1 hour, 1 day and 1 week by using a 3D laser scanner and Premium software.

A total of 45 master casts were obtained from 3 groups of medium-body elastomeric impression materials were divided equally into 15 specimens each:

Group I: The stone casts poured from vinylpolysiloxane impression material.

Group II: The stone casts poured from Polyether impression material.

Group III: The stone casts poured from vinylsiloxanether impression material. 


\section{International Journal of Science and Research (IJSR) \\ ISSN (Online): 2319-7064 \\ Index Copernicus Value (2013): 6.14 | Impact Factor (2015): 6.391}

Each group was subdivided equally into three subgroups of 5 specimens each:

Subgroup A: The master casts obtained from poured after 1 hour.

Subgroup B: The master casts obtained from poured after 1 day.

Subgroup C: The master casts obtained from poured after 1 week.

In the present study the maxillarydentulous typodont jaw, was used as a standard model. Which modified by making five reference points, by using dental milling machine, to make holes with $1.0 \mathrm{~mm}$ depth and $1.0 \mathrm{~mm}$ width on the five marked points (Reference Points) Fig.(1):

1) Mesial triangular fossa of right first molar tooth (RFM).

2) Mesial triangular fossa of left first molar tooth (LFM).

3) Cingulum of right central incisor (RCI).

4) Anterior median palatine region of standard model (AMP).

5) Posterior median palatine region of standard model (PMP).

Autopolymerized acrylic resin custom tray of thickness $3 \mathrm{~mm}$ was fabricated over spacer uniformly $4 \mathrm{~mm}$ from base plate wax to provide space in between the occlusal surface of teeth and inner tray walls, and four stoppers were cut out in spacer, to ensure uniform thickness of the impression material and enabled accurate positioning of the tray. Then tray was perforated, and leaved at least 24 hours before the impressions to allow them to become dimensionally stable, and the spacer was removed by scalpel knife from tray.

On the custom tray, the tray adhesive supplied by the elastomeric impression materials manufacturer was thinly and evenly applied over the inner surface and extending on the periphery of the tray, the adhesive was allowed to dry before the impressions were made.

The elastomeric impression materials were mixed according to the manufacturers specifications. The Vinylpolysiloxane (Elite ${ }^{\circledR}$ HD + Monophase)and Vinylsiloxanether(Identium ${ }^{\circledR}$ Medium) impression materials, mixed byusing auto mixing 1:1 cartridge and an automatic dispensing gun, the suitable amount were injected into the tray. The tray was then seated on standard model and held in place to setting time of manufacturers' instructions. The Polyether(Impregum ${ }^{\mathrm{TM}}$

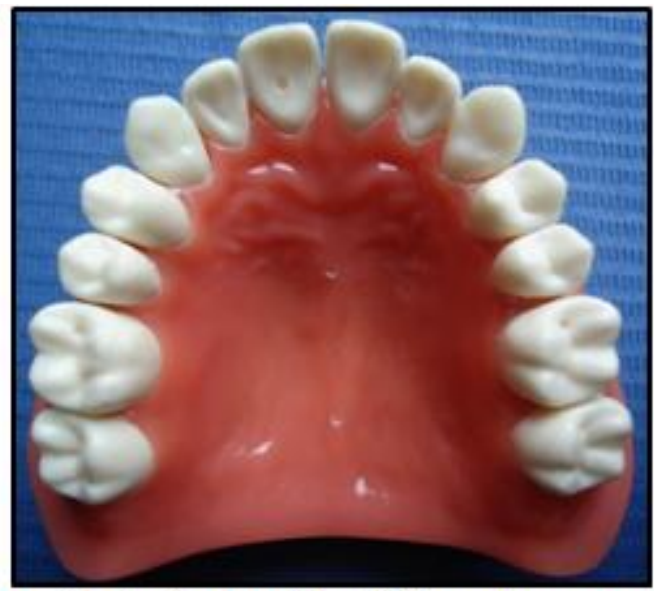

Figure 1: standard model with Five reference points
Soft) impression material, mixed by the hand mix technique, then loaded in the tray, then seated on the standard model, and held in place according to setting time of manufacturers' instruction.

The manufacturers' setting time was doubled to compensate for impression fabrication at room temperature instead of the mouth temperature. After that, the tray was separated from the model.

The same steps were repeated by same tray to three elastomeric impression materials, and impression was stored to 1 hour, 1 day and 1 week in incubator temperature $\left(25^{\circ} \mathrm{C}\right)$ before poured.

After that was poured with extra-hardstone (Type IV, Elite ${ }^{\circledR}$ rock).The mixture was hand spatulated with a round end, stiff blade spatula for 60 seconds, followed by mixing under vacuum mixer for 30 seconds to avoid any air bubbles entrapment. The mixture was poured on a vibrator and allowed to complete set after that pouring base and trimming excess. After hardening of the stone, the cast was separated from tray, and impression material was removed from tray and the tray was cleaned.

The same steps were repeated to all elastomeric impression materials in order to obtain master stone casts poured after 1 days and 1 week.

The standard model and all the master stone casts were digitized automatically by using the 3D laser scanner (Activity Scanner), finally, computer-aided design(CAD) software(Smart Optic) was used to produce virtual3D images of the model and casts, then saved in fully-open STL files. The virtual3Dimages from the digitizer were processed with special software (Premium Software). Where the 3D image of the standard model was superimposed and automatic alignment with one of the 3D images of the master stone casts, then can see the different colors. Fig.(2)On the two aligned images were set of measured point in the center of the holes of five reference points. Fig.(3)Then the difference between the reference points was calculated automatically. This superimposition were repeated for each master stone casts and differences were calculated. Fig.(4)

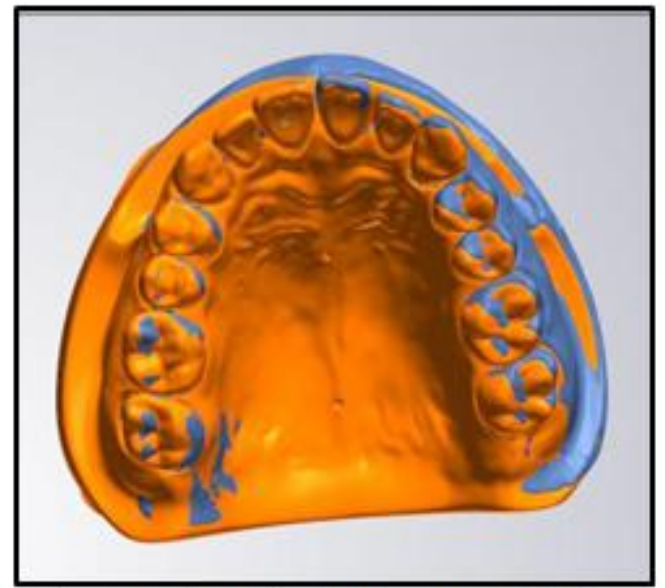

Figure 2: The superimposing3D images with different colors

\section{Volume 5 Issue 7, July 2016




\section{International Journal of Science and Research (IJSR) \\ ISSN (Online): 2319-7064}

Index Copernicus Value (2013): 6.14 | Impact Factor (2015): 6.391

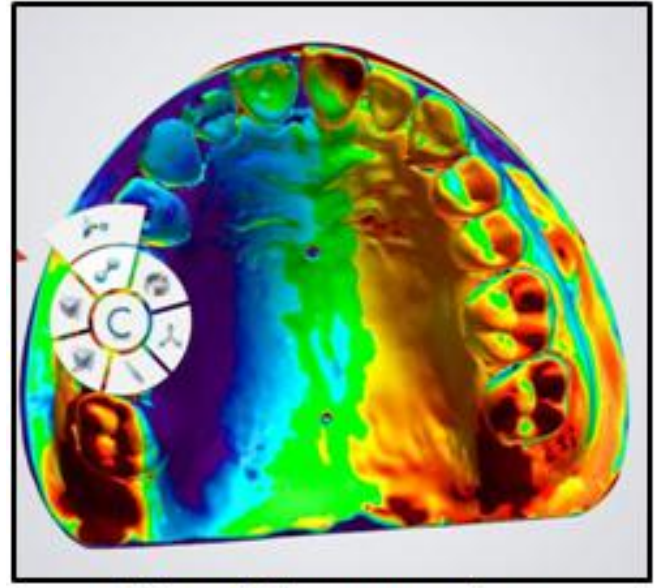

Figure 3: Setmeasure points.

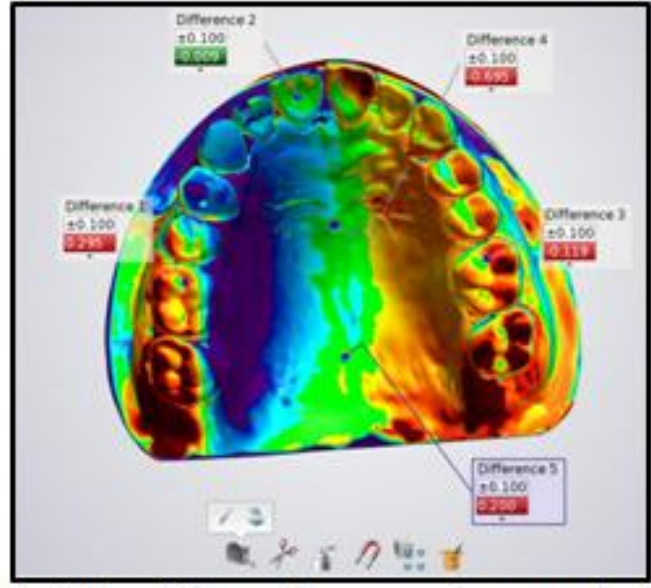

Figure 4: The difference between reference points were calculated automatically.

Table (1) Show the comparison of the mean reference points changes in (fractional $\mathrm{mm}$ ), of vinylpolysiloxane impression material in the all periods of observations. There were insignificant changes of positions of reference points of the casts obtained from vinylpolysiloxane impression material after 1 hour, after 1 day and after 1 week.

Data were fed to the computer and analyzed using IBM SPSS software package version 20.0. Quantitative data were described using range (minimum and maximum), mean and standard deviation. Significance of the obtained results was judged at the $5 \%$ level.

Table 1: Comparison between the reference points changes in (frcational $\mathrm{mm}$ ) of Vinylpolysiloxane impression material after all periods of observations.

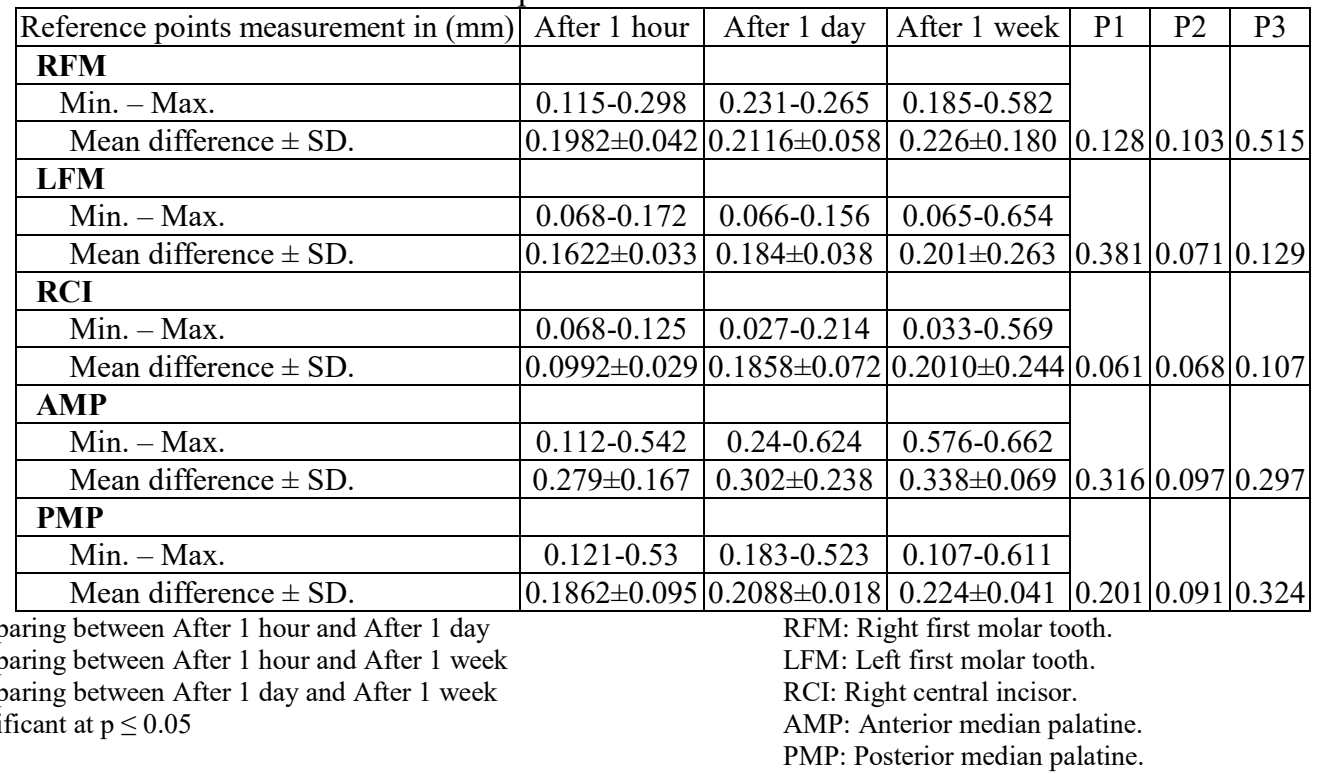

Table (2) Show the comparison of the mean reference points changes in (fractional $\mathrm{mm}$ ), of polyether impression material in the all periods of observations. There were insignificant changes of positions of reference points of the casts obtained from polyether impression material after 1 hour and 1 day. While there was significant changes of these reference points after 1 week. 


\section{International Journal of Science and Research (IJSR) \\ ISSN (Online): 2319-7064 \\ Index Copernicus Value (2013): 6.14 | Impact Factor (2015): 6.391}

Table 2: Comparison between the reference points changes in (frcational $\mathrm{mm}$ ) of polyether impression material after all periods of observations.

\begin{tabular}{|c|c|c|c|c|c|c|}
\hline Reference points measurement in (mm) & After 1 hour & After 1 day & After 1 week & $\mathrm{P} 1$ & $\mathrm{P} 2$ & P3 \\
\hline RFM & & & & \multirow[b]{3}{*}{0.150} & \multirow[b]{3}{*}{$0.021^{*}$} & \multirow[b]{3}{*}{0.044} \\
\hline Min. - Max. & $0.067-0.18$ & $0.25-0.323$ & $0.087-0.426$ & & & \\
\hline Mean difference \pm SD. & $0.1802 \pm 0.049$ & $0.238 \pm 0.031$ & $0.3184 \pm 0.139$ & & & \\
\hline \multicolumn{4}{|l|}{ LFM } & \multirow[b]{3}{*}{0.101} & \multirow[b]{3}{*}{$0.0021^{*}$} & \multirow[b]{3}{*}{$0.038^{*}$} \\
\hline Min. - Max. & $0.097-0.293$ & $0.119-0.191$ & $0.068-0.587$ & & & \\
\hline Mean difference \pm SD. & $0.179 \pm 0.073$ & $0.2358 \pm 0.030$ & $0.3034 \pm 0.216$ & & & \\
\hline \multicolumn{4}{|l|}{ RCI } & \multirow[b]{3}{*}{0.062} & \multirow[b]{3}{*}{$0.013^{*}$} & \multirow[b]{3}{*}{$0.032^{*}$} \\
\hline Min. - Max. & $0.003-0.158$ & $0.031-0.19$ & $0.107-0.481$ & & & \\
\hline Mean difference \pm SD. & $0.0919 \pm 0.063$ & $0.1864 \pm 0.062$ & $0.287 \pm 0.148$ & & & \\
\hline \multicolumn{4}{|l|}{ AMP } & \multirow[b]{3}{*}{0.131} & \multirow[b]{3}{*}{$0.013^{*}$} & \multirow[b]{3}{*}{$0.011^{*}$} \\
\hline Min. - Max. & $0.0848-0.681$ & $0.146-0.88$ & $0.176-0.814$ & & & \\
\hline Mean difference \pm SD. & $0.25996 \pm 0.241$ & $0.3162 \pm 0.307$ & $0.5162 \pm 0.279$ & & & \\
\hline \multicolumn{4}{|l|}{ PMP } & \multirow[b]{3}{*}{0.108} & \multirow[b]{3}{*}{$0.006^{*}$} & \multirow[b]{3}{*}{$0.021^{*}$} \\
\hline Min. - Max. & $0.012-0.598$ & $0.146-0.781$ & $0.143-0.742$ & & & \\
\hline Mean difference \pm SD. & $0.2540 \pm 0.190$ & $0.3062 \pm 0.105$ & $0.539 \pm 0.197$ & & & \\
\hline
\end{tabular}

$\mathrm{p}_{1}$ : $\mathrm{p}$ value for comparing between After 1 hour and After 1 day

$\mathrm{p}_{2}$ : $\mathrm{p}$ value for comparing between After 1 hour and After 1 week

RFM: Right first molar tooth.

$\mathrm{p}_{3}$ : $\mathrm{p}$ value for comparing between After 1 day and After 1 week

LFM: Left first molar tooth.

*: Statistically significant at $\mathrm{p} \leq 0.05$

RCI: Right central incisor.

AMP: Anterior median palatine.

PMP: Posterior median palatine.

Table (3) Show the comparison of the mean reference points changes in (fractional $\mathrm{mm}$ ), of vinylsiloxanether impression material in the all periods of observations. There were insignificant changes of positions of reference points of the casts obtained from vinylsiloxanether impression material after 1 hour and 1 day. While there was significant changes of these reference points after 1 week only in two reference points.

Table 3: Comparison between the reference points changes in (frcationalmm) of vinylsiloxanether impression material after all periods of observations.

\begin{tabular}{|c|c|c|c|c|c|c|}
\hline Reference points measurement in $(\mathrm{mm})$ & After 1 hour & After 1 day & After 1 week & $\mathrm{P} 1$ & $\mathrm{P} 2$ & P3 \\
\hline \multicolumn{4}{|l|}{ RFM } & \multirow[b]{3}{*}{0.265} & \multirow[b]{3}{*}{0.087} & \multirow[b]{3}{*}{0.042} \\
\hline Min. - Max. & $0.015-0.239$ & $0.069-0.298$ & $0.137-0.211$ & & & \\
\hline Mean difference \pm SD. & $0.1582 \pm 0.004$ & $0.178 \pm 0.013$ & $0.2498 \pm 0.032$ & & & \\
\hline \multicolumn{4}{|l|}{ LFM } & \multirow[b]{3}{*}{0.075} & \multirow[b]{3}{*}{0.066} & \multirow[b]{3}{*}{0.201} \\
\hline Min. - Max. & $0.013-0.248$ & $0.019-0.211$ & $0.148-0.378$ & & & \\
\hline Mean difference \pm SD. & $0.1311 \pm 0.014$ & $0.141 \pm 0.068$ & $0.2172 \pm 0.153$ & & & \\
\hline RCI & & & & \multirow[b]{3}{*}{0.614} & \multirow[b]{3}{*}{0.107} & \multirow[b]{3}{*}{0.321} \\
\hline Min. - Max. & $0.103-0.167$ & $0.136-0.21$ & $0.146-0.478$ & & & \\
\hline Mean difference \pm SD. & $0.1308 \pm 0.031$ & $0.1616 \pm 0.030$ & $0.248 \pm 0.135$ & & & \\
\hline \multicolumn{4}{|l|}{ AMP } & \multirow[b]{3}{*}{0.165} & \multirow[b]{3}{*}{$0.003^{*}$} & \multirow[b]{3}{*}{$0.015^{*}$} \\
\hline Min. - Max. & $0.121-0.388$ & $0.146-0.331$ & $0.054-0.758$ & & & \\
\hline Mean difference \pm SD. & $0.0506 \pm 0.025$ & $0.0772 \pm 0.027$ & $0.3224 \pm 0.273$ & & & \\
\hline \multicolumn{4}{|l|}{ PMP } & \multirow[b]{3}{*}{0.165} & \multirow[b]{3}{*}{$0.002^{*}$} & \multirow[b]{3}{*}{$0.011^{*}$} \\
\hline Min. - Max. & $0.009-0.488$ & $0.027-0.453$ & $0.126-0.661$ & & & \\
\hline Mean difference \pm SD & $0.0688 \pm 0.136$ & $0.0852 \pm 0.095$ & $0.3562 \pm 0.243$ & & & \\
\hline \multicolumn{6}{|c|}{$\begin{array}{ll}\text { paring between After } 1 \text { hour and After } 1 \text { day } & \text { RFM: Right first molar tooth. } \\
\text { paring between After } 1 \text { hour and After } 1 \text { week } & \text { LFM: Left first molar tooth. } \\
\text { paring between After } 1 \text { day and After } 1 \text { week } & \text { RCI: Right central incisor. } \\
\text { ificant at } \mathrm{p} \leq 0.05 & \text { AMP: Anterior median palatine. } \\
& \text { PMP: Posterior median palatine. }\end{array}$} & \\
\hline
\end{tabular}

Table (4) Show the comparison between the studied elastomeric impression materials according to reference points after 1 hour, there was insignificant difference between the three materials in all reference points. 


\section{International Journal of Science and Research (IJSR) \\ ISSN (Online): 2319-7064 \\ Index Copernicus Value (2013): 6.14 | Impact Factor (2015): 6.391}

Table 4: Comparison between the studied materials according to reference points after 1 hour.

\begin{tabular}{|c|c|c|c|c|c|c|}
\hline Reference points & Polyether & Vinylpolysiloxane & Vinylsiloxanether & P1 & $\mathrm{P} 2$ & P3 \\
\hline \multicolumn{4}{|l|}{ RFM } & \multirow[b]{3}{*}{0.411} & \multirow[b]{3}{*}{0.095} & \multirow[b]{3}{*}{0.107} \\
\hline Min. - Max. & $0.067-0.18$ & $0.115-0.298$ & $0.015-0.239$ & & & \\
\hline Mean difference \pm SD. & $0.1802 \pm 0.049$ & $0.1982 \pm 0.042$ & $0.1582 \pm 0.004$ & & & \\
\hline LFM & & & & \multirow[b]{3}{*}{0.652} & \multirow[b]{3}{*}{0.455} & \multirow[b]{3}{*}{0.314} \\
\hline Min. - Max. & $0.097-0.293$ & $0.068-0.172$ & $0.013-0.248$ & & & \\
\hline Mean difference \pm SD. & $0.179 \pm 0.073$ & $0.1622 \pm 0.033$ & $0.1311 \pm 0.014$ & & & \\
\hline RCI & \multirow{3}{*}{$\begin{array}{c}0.003-0.158 \\
0.0919 \pm 0.063\end{array}$} & & & \multirow[b]{3}{*}{0.236} & \multirow[b]{3}{*}{0.331} & \multirow[b]{3}{*}{0.412} \\
\hline Min. - Max. & & $0.068-0.125$ & $0.103-0.167$ & & & \\
\hline Mean difference \pm SD. & & $0.0992 \pm 0.029$ & $0.1308 \pm 0.031$ & & & \\
\hline \multicolumn{4}{|l|}{ AMP } & \multirow[b]{3}{*}{0.682} & \multirow[b]{3}{*}{0.215} & \multirow[b]{3}{*}{0.336} \\
\hline Min. - Max. & $0.0848-0.681$ & $0.112-0.542$ & $0.121-0.388$ & & & \\
\hline Mean difference \pm SD. & $0.25996 \pm 0.241$ & $0.279 \pm 0.167$ & $0.2406 \pm 0.025$ & & & \\
\hline \multicolumn{4}{|l|}{ PMP } & \multirow[b]{3}{*}{0.321} & \multirow[b]{3}{*}{0.113} & \multirow[b]{3}{*}{0.105} \\
\hline Min. - Max. & $0.012-0.598$ & $0.121-0.53$ & $0.009-0.488$ & & & \\
\hline Mean difference \pm SD. & $0.2540 \pm 0.190$ & $0.1862 \pm 0.095$ & $0.2388 \pm 0.136$ & & & \\
\hline $\begin{array}{l}\text { ng between Polyether and Vin } \\
\text { ng between Polyether and Vin } \\
\text { ng between Vinylpolysiloxane } \\
\text { nt at } p \leq 0.05\end{array}$ & $\begin{array}{l}\text { ylpolysiloxane } \\
\text { ylsiloxanether } \\
\text { and Vinylsilox }\end{array}$ & & $\begin{array}{l}\text { M: Right first molar } \\
\text { M: Left first molar to } \\
\text { I: Right central incis } \\
\text { MP: Anterior median } \\
\text { IP: Posterior median }\end{array}$ & $\begin{array}{l}\text { tooth. } \\
\text { ooth. } \\
\text { or. } \\
\text { palatine }\end{array}$ & & \\
\hline
\end{tabular}

$\mathrm{p} 1$ : $\mathrm{p}$ value for comparing between Polyether and Vinylpolysiloxane

$\mathrm{p} 2$ : $\mathrm{p}$ value for comparing between Polyether and Vinylsiloxanethe

p3: p value for comparing between Vinylpolysiloxane and Vinylsiloxanether

Posterior median palatine.

Table (5) Show the comparison between the studied materials according to reference points after 1 day, there was insignificant difference between the three materials in all reference points.

Table 5: Comparison between the studied materials according to reference points after 1 day.

\begin{tabular}{|c|c|c|c|c|c|c|}
\hline Reference points & Polyether & Vinylpolysiloxane & Vinylsiloxanether & $\mathrm{P} 1$ & $\mathrm{P} 2$ & P3 \\
\hline RFM & & & & \multirow[b]{3}{*}{0.365} & \multirow[b]{3}{*}{0.312} & \multirow[b]{3}{*}{0.081} \\
\hline Min. - Max. & $0.25-0.323$ & $0.185-0.582$ & $0.069-0.298$ & & & \\
\hline Mean difference \pm SD. & $0.278 \pm 0.031$ & $0.226 \pm 0.180$ & $0.178 \pm 0.013$ & & & \\
\hline \multicolumn{4}{|l|}{ LFM } & \multirow[b]{3}{*}{0.365} & \multirow[b]{3}{*}{0.510} & \multirow[b]{3}{*}{0.331} \\
\hline Min. - Max. & $0.119-0.191$ & $0.066-0.156$ & $0.019-0.211$ & & & \\
\hline Mean difference \pm SD. & $0.2658 \pm 0.030$ & $0.184 \pm 0.038$ & $0.141 \pm 0.068$ & & & \\
\hline \multicolumn{4}{|c|}{\begin{tabular}{l|l} 
RCI & \\
\end{tabular}} & \multirow[b]{3}{*}{0.582} & \multirow[b]{3}{*}{0.425} & \multirow[b]{3}{*}{0.362} \\
\hline Min. - Max. & $0.031-0.19$ & $0.027-0.214$ & $0.136-0.21$ & & & \\
\hline Mean difference \pm SD. & $0.1864 \pm 0.062$ & $0.1858 \pm 0.072$ & $0.1616 \pm 0.030$ & & & \\
\hline \multicolumn{4}{|l|}{ AMP } & \multirow[b]{3}{*}{0.352} & \multirow[b]{3}{*}{0.061} & \multirow[b]{3}{*}{0.211} \\
\hline Min. - Max. & $0.146-0.88$ & $0.24-0.624$ & $0.146-0.331$ & & & \\
\hline Mean difference \pm SD. & $0.4162 \pm 0.307$ & $0.302 \pm 0.238$ & $0.2772 \pm 0.027$ & & & \\
\hline \multicolumn{4}{|l|}{ PMP } & \multirow[b]{3}{*}{.065} & \multirow[b]{3}{*}{0.070} & \multirow[b]{3}{*}{.336} \\
\hline Min. - Max. & $0.146-0.781$ & $0.183-0.523$ & $0.027-0.453$ & & & \\
\hline Mean $\mathrm{d}$ & $0.4062 \pm 0.105$ & 0.20 & $0.2452 \pm 0$ & & & \\
\hline
\end{tabular}

$\mathrm{p} 1: \mathrm{p}$ value for comparing between Polyether and Vinylpolysiloxane

RFM: Right first molar tooth.

$\mathrm{p} 2$ : $\mathrm{p}$ value for comparing between Polyether and Vinylsiloxanethe

LFM: Left first molar tooth.

RCI: Right central incisor.

AMP: Anterior median palatine.

*: Statistically significant at $\mathrm{p} \leq 0.05$

PMP: Posterior median palatine.

Table (6) Show the comparison between the studied materials according to reference points after 1 week, there was insignificant difference between the three materials in all measurement points. There was insignificant difference between the three materials in all reference points.

Table 6: Comparison between the studied materials according to points after 1 week.

\begin{tabular}{|c|c|c|c|c|c|c|}
\hline Reference points & Polyether & Vinylpolysiloxane & Vinylsiloxanether & P1 & P2 & P3 \\
\hline RFM & & & & \multirow[b]{3}{*}{0.211} & \multirow[b]{3}{*}{0.213} & \multirow[b]{3}{*}{0.418} \\
\hline Min. - Max. & $0.087-0.426$ & $0.185-0.682$ & $0.137-0.211$ & & & \\
\hline Mean difference \pm SD. & $0.3184 \pm 0.139$ & $0.216 \pm 0.180$ & $0.2498 \pm 0.032$ & & & \\
\hline \multicolumn{4}{|l|}{ LFM } & \multirow[b]{3}{*}{0.107} & \multirow[b]{3}{*}{0.132} & \multirow[b]{3}{*}{0.411} \\
\hline Min. - Max. & $0.068-0.587$ & $0.065-0.654$ & $0.148-0.378$ & & & \\
\hline Mean difference \pm SD. & $0.3034 \pm 0.216$ & $0.201 \pm 0.263$ & $0.2172 \pm 0.153$ & & & \\
\hline \multicolumn{4}{|l|}{ RCI } & \multirow[b]{3}{*}{0.682} & \multirow[b]{3}{*}{0.511} & \multirow[b]{3}{*}{0.496} \\
\hline Min. - Max. & $0.107-0.481$ & $0.033-0.569$ & $0.146-0.478$ & & & \\
\hline Mean difference \pm SD. & $0.287 \pm 0.148$ & $0.2010 \pm 0.244$ & $0.248 \pm 0.135$ & & & \\
\hline \multicolumn{4}{|l|}{ AMP } & \multirow[b]{3}{*}{0.325} & \multirow[b]{3}{*}{0.092} & \multirow[b]{3}{*}{0.618} \\
\hline Min. - Max. & $0.176-0.814$ & $0.576-0.662$ & $0.054-0.758$ & & & \\
\hline Mean difference \pm SD. & $0.5162 \pm 0.279$ & $0.338 \pm 0.069$ & $0.3724 \pm 0.273$ & & & \\
\hline \multicolumn{4}{|l|}{ PMP } & \multirow[b]{3}{*}{$0.021^{*}$} & \multirow[b]{3}{*}{0.063} & \multirow[b]{3}{*}{0.105} \\
\hline Min. - Max. & $0.143-0.742$ & $0.107-0.611$ & $0.126-0.661$ & & & \\
\hline Mean difference \pm SD & $0.539 \pm 0.197$ & $0.224 \pm 0.041$ & $0.3562 \pm 0.243$ & & & \\
\hline
\end{tabular}

Volume 5 Issue 7, July 2016

www.ijsr.net

Licensed Under Creative Commons Attribution CC BY 


\section{International Journal of Science and Research (IJSR) \\ ISSN (Online): 2319-7064}

Index Copernicus Value (2013): 6.14 | Impact Factor (2015): 6.391

$\mathrm{p} 1: \mathrm{p}$ value for comparing between Polyether and Vinylpolysiloxane $\mathrm{p} 2$ : $\mathrm{p}$ value for comparing between Polyether and Vinylsiloxanether p3: $\mathrm{p}$ value for comparing between Vinylpolysiloxane and Vinylsiloxanether *: Statistically significant at $\mathrm{p} \leq 0.05$

\section{Discussion}

The overall goal of a dental impression is to produce a three dimensional exact negative replica of hard and soft tissue of the oral cavity.[4]The most critical properties of elastomeric impression materials are accuracy, dimensional stability, and tear strength (elastic recovery).[5]

The aim of this laboratory study was conducted onmaxillary dentulous typodont model to evaluate and compare the dimensional changes of three different elastomeric impression materials after poured 45 impressionsat 1 hour, 1 day and 1 week by using three-dimensional (3D) laser scanner and three-dimensional superimpositional software.

In most of the studies reported in literature so far, precision measurement was done using instruments such as travelling microscope,[6,7] micrometer,[8] vernier caliper,[9] and laser probes. There have been very few studies to this date assessing the accuracy of impression materials using the laser digitizers. In the present study was used 3D laser scanner to assess dimensional accuracy of casts that obtained from elastomeric impression materials.

The scanning laser 3Dscanner can delineate $\mathrm{x}, \mathrm{y}$ and $\mathrm{z}$ coordinates from a specimen without actually contacting the surface. The digitizer automatically tracks coordinates with precision and stores data as the number of points on a surface.[1]

All elastomeric impression materials experience shrinkage during setting.[10]Rearrangement of the bonds and release of volatile byproducts during polymerization account for the shrinkage.[11]

Custom trays provide uniformity of materials which minimizes the dimensional changes that might distort an impression. Gilmore [12] explained the use of custom tray produced dies that were much more accurate than the stock trays.

Accuracy decreased as the thickness of material increased so material should be uniform all over the surface. De Araujo, assessed the effect of material bulk and undercuts on the accuracy of impression materials. [7]

The results of the present study showed that there was a statistically insignificant difference between mean difference of the casts obtained from the vinylpolysiloxane impression material in all of periods of observations, the deviation of the reference points of master casts from the standard model could be due to continued polymerization shrinkage, but these were relatively small. In polyether impression material was found statistically significant difference, with increase in mean difference when comparing after 1 hour with data of after 1 week, and when comparing after 1 day with after 1 week. Dimensional stability of impression material was noted, but should be poured only once within 1 day after impression making
RFM:Right first molar tooth

LFM: Left first molar tooth.

RCI: Right central incisor.

AMP: Anterior median palatine.

PMP: Posterior median palatine.

because of the distortion of the material that occurs over time (after 1 week). The reason of distortion due to absorption of water and leaching out of water soluble plasticizers. Thus, leading to further shrinkage of impressions. (13)

In case of vinylsiloxanether, show statistically insignificant difference in all mean difference expect in two reference points which has statistically significant difference, with excessive increase in difference measurement, when comparing after 1 hour with after 1 week and when comparing after 1 day with after 1 week.

The results were in agreement with Rodriguez in vitro study who concluded that polyvinylsiloxane was dimensionally stable impression material.[1]

Earlier studies also were in harmony with these findings since they indicated that polyvinylsiloxane have demonstrated very good dimensional accuracy.[3,1519] Whereas, my finding was in disagreement with the work of others who reported that polyethers were more accurate than polyvinylsiloxane materials.[20]Ritter 2000[21] and Panichuttra1991.[17]

\section{Conclusions}

1) All reference points on the master casts obtained from all elastomeric impression materials after one hour and one day showed little changes than the standard model.

2) Concerning the time intervals for pouring the elastomeric impression materials. Both polyether and vinylsiloxanether showed significant changes of difference points after one week of pouring the impressions.

3) The vinylpolysiloxane impression material doesn't showed these changes after one week which means that its dimensional stable than the other one.

\section{References}

[1] Shah S, Sundaram G, Bartlett D, sherriff M. The use of a 3D laser scanner using superimpositional software to assess the accuracy of impression techniques. J Dent 2004; 32: 653-8.

[2] DI Felice R, Scotti, R, Belser UC. The influence of the mixing technique on the content of voids in two polyether impression materials. SchweizMonatsschrZahnmed 2002; 112: 12-6.

[3] Craig RG. Review of dental impressionmaterials. Adv Dent Res 1988; 2: 51-64.

[4] Kang AH, Johnson GH, Lepe X, Wataha JC. Accuracy of a reformulated fast-set vinyl polysiloxane impression material using dual-arch trays. J Prosthet Dent 2009; 101(5): 332-41.

[5] Hondrum SO. Tear and energy properties of three impression materials. Int J Prosthodont 1994;7: 517-21.

[6] Anusavice KJ. Philips Science of dental materials. 10th edition. W.B. Saunders Co. Philadelphia. 1996. 
[7] De Araujo A, Jorgenson E. Effect of material bulk and undercuts on the accuracy of impression materials. J. Prosthet Dent 1985; 54 (6): 791-94.

[8] Adriana Claudia Lapria Faria. Accuracy of stone casts obtained from different impression materials. Braz Oral Res 2008; 22(4):293.

[9] Carrotte PV, Johnson A, Winstanley RB. The influence of the impression tray on the accuracy of impressions for crown and bridge work - an investigation and review. British Dental Journal 1998; 185: 580-585.

[10] Burgess JO. Impression Material Basics. Inside Dent 2005; 30-3.

[11] Powers JM, Sakaguchi RL. Craig's restorative dental materials. 12th ed. Philadelphia: Mosby Elsevier, 2006.

[12] Gilmore, Schnell and Philips. Factors influencing the accuracy of silicone impression materials. J Prosthet Dent 1959; 9(2):304-313

[13] Pandita A, Jain T, Yadav NS, Feroz SMA, Pradeep, Diwedi A. Evaluation and Comparison of Dimensional Accuracy of Newly Introduced Elastomeric Impression Material using 3D Laser Scanners: An in vitro Study. J Contemp Dent Pract 2013;14(2):265-268.

[14] Rodriguez JM, Bartlett DW. The dimensional stability of impression materials and its effect on in vitro tooth wear studies. Dent Mater 2011; 27:253-58.

[15] Pratten DH, Novetsky M. Detail reproduction of soft tissue: a comparison of impression materials. J Prosthet Dent 1991; 65: 188-91.

[16] Chai J, Takahashi Y, Lautenschlager EP: Clinical relevant mechanical properties of elastomeric impression materials. Int J Prosthodont 1998;11:219223.

[17] Panichuttra R, Jones RM, Goodacre C, Munoz CA, Moore KB. Hydrophilic polyvinyl siloxane impression materials dimensional accuracy, wettability and effect on gypsum hardness. Int J Prosthodont 1991;4:240-8.

[18]Chong YH, Soh G, Setchell DJ, Wickens JL. The relationships between contact angles of die stone on elastomeric impression materials and voids on stone casts. Dent Mater 1990;6:166.

[19] Lepe X, Johnson GH, Berg JC, Aw TC, Stroh GS. Wettability, imbibition and mass change of disinfected low viscosity impression materials. J Prosthet Dent 2002;88:268-76.

[20] Habib AN, Shehata MT. The effect of the type and technique used for impression making on the accuracy of elastomeric impression materials. Egyptian Dental Journal 1995; 41:1409-16.

[21]Ritter AV, Swift EJ. Medium-viscosity polyether impression material: a case report. Compendium 2000; 21: 993-1004.

\section{Author Profile}

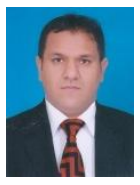

Abd Elsalam Awad Ali Abd Elsalam, received the B.D.S. In Dental and Oral Surgery from Benghazi University, Faculty of dentistry, 2009. During 2009. 2012, he practiced in Ministry of Health, Benghazi Libya. During 2012 till now, he educated for M.S degree in prosthodontics in prosthetic department, Faculty of dentistry. Alexandria University. 